\title{
The early results of surgical treatment of congenital clubfoot by a modified soft tissue release
}

\begin{abstract}
Background and objective: Talipes Equinovarus (TEV) or Congenital Clubfoot is the most common congenital anomaly of the foot. The incidence of TEV is 1-2 per 1000 life births, about $30 \%$ of these cases is bilateral with a higher incidence in males than in females (2:1). Congenital Clubfoot is a complex deformity which has four components: Heel in equinus, hind foot in varus, mid foot in cavus, forefoot in adduction and supination. The presented study aimed to evaluate the surgical treatment outcome of congenital club foot by a modified soft tissue release (i.e. division of tendons of tibialis posterior and flexor hallucis longus).
\end{abstract}

Methods: This is a prospective study done on the Result of treatment of congenital Clubfoot by soft tissue release. Numbers of patients are thirty three patients, forty eight feet, fifteen patients $(45.46 \%)$ had bilateral, and eighteen patients $(54.55 \%)$ had unilateral deformities. Twenty one patients (63.64) were male and twelve patients (36.37) were female, male to female ratio was 1.75:1, their ages range between 4-35 months (mean ages in months $=15.43$ months). The patients whom included in this study had no previous treatment because of delay in presentation.

Results: All patients were assessed clinically and radiologically. The result of our study was as follow: Excellent result for 28 feet (58.3\%), Good result for 16 feet $(33.3 \%)$, Poor result for 4 feet $(8.3 \%)$. The over all result can be sub divided to two categories; a) satisfactory which involve both the excellent result and the good result $(91.67 \%)$ and $b$ ) unsatisfactory result which involve only the poor result $(8.33 \%)$.

Conclusion: The study revealed that the use of this surgical method is of good result and lower rate of complication.

Keywords: club foot soft tissue release, pop.

\section{Introduction}

The clubfoot is classified according to it is etiology. Evaluation involves measuring the foot (i.e. the size, shape, ranges of motion of the joints, and radiographic angles). Radiological examination useful for the assessment of deviation degree and reduction criteria. The anteroposterior (AP) view shows subtalar opening angle below $20^{\circ}$. The lateral view shows talocalcaneal angle above $35^{\circ}$. The treatment of clubfoot is controversial and continues to be one of the biggest challenges in pediatric orthopaedics. This controversy is due in part to the difficulty in measuring and evaluating the effectiveness of different treatment methods. The heart of the debate is a lack of understanding of the functional anatomy of the deformity, the biological response of young connective tissue to injury and repair, and their combined effect on the long-term treatment outcomes ${ }^{1}$. The goal of treatment is to reduce or eliminate the deformity so that the patient has a functional, pain-free, plantigrade foot, with good mobility and without calluses, and does not need to wear modified shoes ${ }^{2}$. The treatment of clubfoot should be started as early as possible; preferably within a day or tow of

*Department of Surgery, College of Medicine, Hawler Medical University, Erbil, Iraq 
birth. This consists of non surgical method by repeated manipulation and adhesive strapping which maintain correction; resistant cases will declare themselves after 8 to 12 weeks of serial manipulation and casting ${ }^{3}$. Another method of treatment is surgical intervention, and the objectives of surgical treatment are (i) the complete release of the joint tethers (capsular and ligamentous contractures and fibrotic bands) and (ii) lengthening of tendons so that the foot can be positioned normally without undue tension ${ }^{4}$. the Aim of Study is :

1. To evaluate the surgical treatment outcome of congenital club foot by a modified soft tissue release (i.e. division of tendons of tibialis posterior and flexor hallucis longus).

2. To compare this method with other surgical methods used in treatment of congenital clubfoot.

3. To show the benefits in this method that it needs less extensive dissection and shorter time of surgery; in consequence less soft tissue injury, contractures, fibrosis and other complications.

\section{Methods}

This is a prospective study done in Erbil teaching hospital and private hospital on the Result of treatment of congenital Clubfoot by soft tissue release. The patients recruited and treated over ten months (August 2008 to June 2009).

-Number of patients are thirty three patients, forty eight feet, fifteen patients $(45.46 \%)$ had bilateral, and eighteen patients $(54.55 \%)$ had unilateral deformities. Twenty one patients (63.64) were male and twelve patients (36.37) were female, male to female ratio was $1.75: 1$, their ages range between 4-35 months (mean ages in months $=15.43$ months).

-The patients whom included in this study had no previous treatment because of delay in presentation and four patients $(12.13 \%)$ had associated congenital anomaly in the form of DDH (which treated conservatively).
-The feet were graded according to Dimeglio's grading system ${ }^{5}$, nine feet (18.75) was grade II and thirty nine feet (81.25) was grade III. We exclude Grade I because it is mild or postural, not requiring surgery and Grade IV because of no available cases.

Dimeglio's grading system depends on evaluation of equinus and varus

\section{Equinus:}

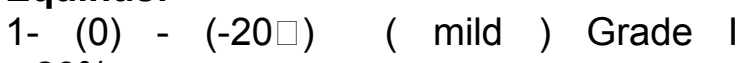
$20 \%$

2- $(20 \square)-(0 \square) \quad$ ( moderate ) Grade II $33 \%$

3- $(45 \square)-(20 \square) \quad$ ( severe ) Grade III $35 \%$

4- $(90 \square)-(45 \square)$ ( very severe) Grade IV $12 \%$

Varus:

(0) $-\left(-20^{0}\right)$ ( mild )

$(20 \square)-\left(0^{\circ}\right)$ ( moderate )

$(45 \square)-\left(20^{\circ}\right)$ ( severe )

$(90 \square)-\left(45^{\circ}\right)(\text { very severe })^{5}$

Inclusion Criteria:

1.Patients of both sexes.

2.Unilateral and bilateral cases.

3.Age between 3months to 36 months.

4.Grade II and Grade III cases according to Dimeglio's grading system. ${ }^{5}$

Associated congenital anomaly like DDH.

\section{Exclusion Criteria:}

1. Age below 3 months and above 36 months.

2. Grade I and grade IV cases according to Dimeglio's grading system.

3. Associated congenital anomalies like arthrogryposis, tibial deficiency, meningocele and constriction rings.

4. Traumatic clubfoot. 


\section{Results}

1. Male to female ratio was $1.75: 1$, their ages range between 4-35 months, the statistics shown in Table 1.

Table 1: Age group statistics

$\begin{array}{ll}\text { Mean } & 15.51515152 \\ \text { Standard Error } & 1.451306368 \\ \text { Median } & 14 \\ \text { Mode } & 14 \\ \text { Standard Deviation } & 8.337120352 \\ \text { Minimum } & 4 \\ \text { Maximum } & 35\end{array}$

The feet were graded according to (Dimeglio's grading system) $\square$, nine feet $(18.75 \%)$ was grade II and thirty nine feet $(81.25 \%)$ was grade III. We exclude Grade I because it is mild or postural, not requiring surgery and Grade IV because of no available cases.

- All patients were assessed radiologically Table 3 and clinically according to Beatson and Pearson criteria of assessment of the results, our treatment were as follows:

1. Excellent- Normal function and appearance.

2. Good- Normal function with a plantigrade foot, no fixed deformity and the ability to dorsiflex and evert the foot to the neutral position (it is differ from excellent feet only in appearance).

3. Poor- Activity limited in any way; residual fixed deformity, such as hindfoot equinus, heel inversion, forefoot adduction, varus; inability to dorsiflex and evert the foot to the neutral position ${ }^{1}$.

The result of our study was as follow Table 4:

1. Excellent result for 28 feet $(58.3 \%)$.

2. Good result for 16 feet $(33.3 \%)$.

3. Poor result for 4 feet $(8.3 \%)$, these feet were classified as poor result because they developed residual deformity in form of forefoot adduction and the cause was improper application of corrective cast.

The result of age group (0-6 months) from our sample was all of them excellent, and for age group (7-12 months), ten feet was of excellent result and five feet of good result, while for age group (13 months and above), thirteen feet was of excellent result, eleven feet of good result and four feet of poor result. This means that the younger the age the better the result. Table 4. Chi square tests shown in Table 5

Table 2: Radiological data.

\begin{tabular}{lll} 
& X-ray AP & X-ray Lat. \\
\hline No. & 48 & 48 \\
Mean & 34,69 & 40,52 \\
Median & 35.00 & 41,00 \\
Std. Deviation & 5,211 & 4,895 \\
Minimum & 20 & 25 \\
Maximum & 45 & 48
\end{tabular}

Table 3: The out come of surgical treatments.

\begin{tabular}{lll} 
Result & Frequency & Percent \\
\hline Excellent & 28 & 58.3 \\
Good & 16 & 33.3 \\
Poor & 4 & 8.4 \\
Total & 48 & 100.0
\end{tabular}

Table 4: Distribution of samples by age versus the result

\begin{tabular}{lllll}
$\begin{array}{l}\text { Age } \\
\text { group in } \\
\text { months }\end{array}$ & $\begin{array}{l}\text { No. } \\
\text { of } \\
\text { feet }\end{array}$ & Excellent & Good & Poor \\
\hline $0-6$ & 5 & $5(100 \%)$ & $0(0 \%)$ & $0(0 \%)$ \\
$7-12$ & 15 & $10(66.67 \%)$ & $5(33.33 \%)$ & $0(0 \%)$ \\
13 and & 28 & $13(46.43 \%)$ & $11(39.28)$ & $4(14.29 \%)$ \\
above & & & &
\end{tabular}

Table 5: chi - square tests

\begin{tabular}{llll} 
& X & df & P \\
\hline Pearson Chi- Square & 6.244 & 4 & 0.182 \\
Likelihood & 8.551 & 4 & 0.073 \\
Linear-by-linear & 5.522 & 1 & 0.019 \\
Association & & & \\
No. of valid cases & 48 & & \\
\hline
\end{tabular}




\section{Discussion}

Talipes Equinovarus (TEV) or Congenital Clubfoot is the most common congenital anomaly of foot. The treatment of clubfoot is controversial and continues to be one of the biggest challenges in pediatric orthopaedics. The goal of treatment of club foot is to reduce or eliminate the deformity so that the patient has a functional, painfree, plantigrade foot, with good mobility and without calluses, and does not need to wear modified shoes. The treatment of TEV should be started as soon as possible from first or second day of life by conservative method. In our study we used surgical treatment (Posteromedial soft tissue release, Turco incision, lengthening of tendo-Achilles, posterior capsulotomy, talo-navicular ligament release and surgical release (i.e. division) of tendons of tibialis posterior and flexor hallucis longus) for cases were had been delayed in presentation. In our study we treat thirty three patients, forty eight feet, nine of them were of grade II and thirty nine of them were grade III, we got a satisfactory result, which involves both the excellent result and the good result in forty four feet $(91.67 \%)$ and unsatisfactory result which involve only the poor result in only four feet $(8.33 \%)$. This result is similar to that mentioned by H.Yamamoto et al 19946 ${ }^{6}$, from Tokyo Medical and Dental University, Japan, whom did a study on nineteen patients, twenty four club feet with a similar operative technique a part from Z-lengthening of tibialis posterior tendon and flexor hallucis longus tendon instead of dividing it, with insertion of a Kirschner wire through the talus to the first metatarsal transfixing the talonavicular joint. In another study (done by A. J. Harrold, C. J. Walker in St. mary's Hospital, Harrow road, London, 1983) ${ }^{(7)}$ on fifteen feet which treated by soft tissue release (i.e by Z-lengthening of tibialis posterior tendon and flexor hallucis longus tendon, but without fixation of talonavicular joint by Kirschner wire), the satisfactory result was $80 \%$. In another study (done by $\mathrm{E}$. Ippolito et al 2003$)^{8}$, Investigation performed at the Department of Orthopaedic Surgery, University of Rome, Rome, Italy), they did study on two groups, the first group which included thirty tow patients (forty seven feet) was treated conservatively with limited posterior release, the satisfactory result was $43 \%$, the second group which included thirty tow patients (forty nine feet) was treated surgically, the operative technique was performed according to the method described by Codivilla, and later modified by Turco $\square$, the satisfactory result was

\section{Conclusion}

$78 \%$.

For cases which had delayed in presentation beyond 3 months of age or for resistant cases (which declare them selves after 8-12 successive casting and manipulation) the best treatment is by surgical intervention through a posteromedial incision and soft tissue release (i.e division) of contracted tendons and ligaments. The younger the age of the patient the better the result. We recommend that the treatment should be started as early as possible. We recommend the use of this method in surgical intervention for treatment of congenital club foot because it needs less extensive dissection and shorter time of surgery; in consequence less soft tissue injury, contractures, fibrosis and other complication. Application of corrective cast is a must even after the patient start to walk specially at nigh during

\section{References}

1. Beatson, T. R and Pearson, J. R . A Method of Assessing Correction in Club Feet. J. Bone and Joint Surgery British. 1996, 48-B(1): 40-9.

2. Loch miller $C$, Johnston $D$, Scott $A$, Risman $M$, Hecht JT. Genetic epidemiology study of idiopathic talipes equinovarus. Am J Med Genet. 1998;79: 90-6.

3. Apley AG. Apley's system of orthopedics and fracture. Eighth edition; London: Arnold, a member of the Hodder Headline Group. 2004: 488-9.

4. Turco VJ . Resistant congenital club foot - one stage posteromedial release with internal fixation. 
A follow-up report of a fifteen-year experience. J Bone Joint Surg Am 1989;61: 805-14.

5. Dimeglio A, bensahel $H$, Souchet $p$, Mazeau $p$, bonnet $f$ classification of clubfood . J pediatr orthop B 1995; 4: 129-36.

6. H. Yamamato, Takeshi Muneta and Toshiro Ishibashi, Extensile exposure. 2nd ed. Fro Tokyo medical and dental university 1994: $564-589$.

7. A.J. Harrold, C.J. Walker. The use of tissue expander in club-foot surgery. A case report and review. J Bone Joint Surg Br 1983; 72: 574-7.

8. E. Ippolito, Herndon $\mathrm{CH}$, Strong JM. Update on surgical treatment of clubfoot. J Pediatr Orthop B 2003; 4: 17-24.

9.James $H$.beaty. campbell's operative orthopaedic. Vol . II . 1999; 988 - 1008.

10. Kite J. The non-operative treatment of congenital clubfood south Med J 1984; 23: 337.

11. Ponseti IV treatment of congenital clubfood.J Bone joint surg Am 1992; $74:$ 448-54.

12. Simons GW complete subtalar release in club feet part II comparison with less extensive procedures .J Bone joint surgery Am 1989; 67:1056-65. 